\title{
Emprego de indicadores na avaliação do saneamento - Região Hidrográfica Médio Paraíba do Sul
}

\author{
Marcelo Obraczkal; Sofya de Oliveira Machado Pintol; Carine Ferreira Marques'; Alfredo Akira \\ Ohnuma Júnior ${ }^{1}$
}



1. Universidade do Estado do Rio de Janeiro, Rio de Janeiro, Brasil.

\section{Histórico do Artigo:}

Recebido em: 22 de maio de 2018

Resumo: No Brasil, cerca de 55\% dos esgotos ainda é lançada nos rios, sem tratamento. A severa poluição imposta a importantes corpos hídricos contribui para aumento da escassez e dos conflitos relacionados ao uso da água. Para enfrentamento do problema, a moderna gestão dos recursos hídricos vem utilizando instrumentos de gestão e planejamento tais como indicadores na avaliação de questões estratégicas, entre elas, a abrangência e eficiência dos serviços de saneamento prestados. Dessa forma, são gerados subsídios para tomadas de decisão e implementação de ações, apontando inclusive eventual correção de rumo para aperfeiçoamento do sistema. 0 presente trabalho se estrutura a partir do estudo de caso da bacia hidrográfica do Médio Paraíba do Sul, empregando indicadores de saneamento e de saúde para avaliação do estágio/situação em termos da universalização do saneamento nos 18 municípios que a compõem. Apesar de não ser possível identificar uma correlação direta entre os indicadores de saneamento e os de saúde levantados, a metodologia permite comparar os índices dos municípios da bacia, constatando-se que todos os municípios estão inseridos na categoria/estágio inicial de universalização, com exceção de Quatis. No presente caso aqueles de maior porte e capacidade econômica como Valença, Resende e Barra do Piraí apresentam indicadores piores do que municípios de pequeno porte como Quatis, Porto Real e Pinheiral. Entre outras proposições, recomenda-se o aumento da abrangência dessa tipologia de estudo para demais bacias do Paraíba do Sul, cujos resultados poderão ajudar na definição de prioridades nas futuras ações dos Comitês e das respectivas Agências de Bacia.

Palavras-chave: Recursos hídricos, Universalização do Saneamento, Gestão de Bacia Hidrográfica.

\section{Use of indicators on sanitation's assessment - Hydrographic Region Médio Paraíba do Sul}

Abstract: In Brazil, about 55\% of sewage is still dumped in rivers without treatment. Therefore, the severe pollution caused to relevant and strategic water resources contributes to increase water scarcity, thus implementing conflicts related to water use. The modern management of water resources has been increasingly employing management and planning tools to assess strategic issues such as the sewer system/services, including its coverage and efficiency. Those aspects can be measured, monitored by using indicators as well as defining pre-defined goals to be achieved by the sewer system operator. The information obtained may help both decision making and implementation of measures to achieve those goals. By taking the Paraiba do Sul watershed as a case study, this research builds up a ranking based on both sanitation services and health indicators concerning the 18 municipalities involved. Based on the results obtained is possible to verify that all 17 of them are currently in a category which corresponds to the earliest stage of sanitation situation, in a three step scale, exemption to municipality of Quatis, which handles a middle term position. Some of the most important municipalities in the basin are situated among the worst performances although some of the smallest are situated in the first ranking places. Authors highlight the importance of increasing the scope of this study typology to other watershed basins in the Paraiba do Sul River. The results may be utilized in the definition of priorities for further actions of the Basin Committees and their respective watershed executive Agencies.

Keywords: Water resources, Sewer system/services coverage, Watershed Management. 


\section{Empleo de indicadores para evaluación del saneamiento - Demarcación Hidrográfica Medio Paraíba do Sul}

Resumen: En el Brasil, cerca de 50\% de las alcantarillas sanitarias son lanzadas en los ríos, sin tratamiento. La severa contaminación impuesta a importantes cuerpos hídricos contribuye al aumento de la escasez del agua y de los conflictos relacionados a su utilizacion. Para enfrentamiento de ese problema la moderna gestión de los recursos hídricos emplea instrumentos de planificación para evaluar cuestiones estratégicas, entre ellas, abarcamiento y eficiencia de los servicios de saneamiento prestados, que poden ser medidos por medio de indicadores. Tales índices proporcionan subsidios para toma de decisión e implementación de acciones de perfeccionamiento del sistema. A partir del estudio de caso de la cuenca del Medio Paraíba do Sul, el presente trabajo emplea indicadores de saneamiento y de salud, analisando la situación de la universalización del saneamiento en los 18 municipios que la componen. Mientras no sea posible identificar una correlacion directa entre indicadores de saneamiento y de salud adoptados, la metodología empleada permite comparar los índices para cada uno de estes municipios, constatándose que todos se inseren em una categoría/estadio inicial, excepto Quatis. En el presente caso municipios de mayor porte y capacidad económica como Valença, Resende y Barra do Piraí presentan indicadores inferiores do que municipios de pequeño porte como Quatis, Porto Real e Pinheiral. Se puede todavia constatar la importancia de aumentarse la amplitude de esa tipología de estudio para otras cuencas del Río Paraíba do Sul, cuyos resultados podrán ayudar en la definición de prioridades para las futuras acciones de los Comités y de las respectivas Agencias de Cuenca.

Palabras clave: Recursos hídricos, Universalización del saneamiento, Gestión de Cuenca.

\section{INTRODUÇÃo}

Um dos mecanismos para transmissão de doenças se dá por meio da qualidade da água distribuída à população (Ministério da Saúde, 2006). De acordo com o Relatório sobre o Desenvolvimento dos Recursos Hídricos, divulgado a cada três anos, cerca de 10\% das doenças já registradas mundialmente poderia ser evitada caso os governos investissem mais em saneamento básico, higiene e acesso à água de qualidade. A Organização Mundial da Saúde (OMS) define saneamento como sendo o controle de todo e qualquer fator do meio físico do homem que pode exercer ou exerce efeito prejudicial a respeito ao seu bem-estar físico, mental ou social (GUIMARÃES et al, 2007). Com base nesses conceitos, é notória a importância do saneamento como uma abordagem preventiva e na promoção da saúde da população e do meio ambiente.

Por muitos anos o paradigma de abundância que caracterizava a gestão de recursos hídricos no Brasil gerou certa desvalorização no seu gerenciamento, tanto pelos órgãos responsáveis como por grande parte da população. Porém, mais recentemente, ocorreram vários eventos extremos relacionados à água, traduzidos em enchentes de grandes proporções em áreas urbanas, por um lado, e severa escassez de outro, culminando com uma das mais acentuadas crises hídricas da história na Região Sudeste. Foram então aceleradas as discussões sobre a necessidade de uma gestão mais eficaz, visando promover maior segurança 
Emprego de indicadores na avaliação do saneamento - Região Hidrográfica Médio Paraíba do Sul

hídrica e garantia de abastecimento de setores estratégicos. Um dos seus principais focos é a melhoria dos sistemas de saneamento básico, através da coleta e tratamento adequado dos esgotos, de forma a assegurar uma melhor qualidade da água em corpos hídricos, se comprometendo com disponibilidade desses recursos hídricos em quantidade e qualidade necessárias à fruição pelas gerações futuras (Plano Nacional de Recursos Hídricos, 2006). 0 Brasil possui $12 \%$ de toda a água doce acessível do planeta e fornece água potável a apenas 85\% de sua população, segundo dados do SNIS (2016). Em relação ao ano de 2015 houve um aumento de 1,8 milhão de habitantes, correspondendo a um acréscimo de 1,1\%, embora haja ainda um grande contingente de indivíduos sem acesso à água potável em quantidade e qualidade adequadas (ITB, 2017). No que se refere ao esgotamento sanitário, a situação é ainda mais precária: apenas $46 \%$ dos domicílios possuem coleta de esgoto, mesmo tendo sido constatado um aumento de 4,4 milhões de habitantes, correspondendo a acréscimo de 4,4\% em termos de população total atendida (ITB, 2017). No caso do RJ, em média somente 45\% do esgoto é tratado em relação à água consumida, embora $83 \%$ da população sejam abrangidos pela coleta de esgotos (ITB, 2017). De acordo com o estudo Ranking do Saneamento (ITB, 2017), apesar do RJ ter aumentado a coleta de esgoto passando de 78 para 83\%, no período de 2011 a 2015, a evolução do tratamento de esgoto foi negativa, reduzindo-se de 52 para 44,5\%. De acordo com a CNI (2016), o saneamento permanece como o setor de infraestrutura com 0 menor volume de investimentos no Brasil, respaldado por recente estudo do ITB/EX ANTE (2017), que sustenta ser a falta de tratamento do esgoto o problema maior do sistema de saneamento brasileiro. Seu impacto ambiental é imenso e tem crescido ao longo do tempo; o déficit de tratamento é um problema que tem afetado sobremaneira o meio ambiente urbano das cidades brasileiras e a qualidade de seus recursos naturais para o desenvolvimento dos ecossistemas, praias para o turismo, mananciais para o abastecimento humano, entre outros aspectos (ITB/EXANTE, 2017). De acordo com estudo da FIRJAN (2017), a carência de saneamento é um dos fatores impeditivos mais importantes para o desenvolvimento de muitas áreas/regiões no estado fluminense, algumas atualmente em estágio de total estagnação econômica.

Segundo LIMA (2018), tendo em vista o cenário atual de escassez crônica e risco de colapso dos sistemas de abastecimento de água especialmente nas regiões hidrográficas do Atlântico, entre as ações prioritárias é discriminada a efetivação dos investimentos necessários em saneamento para preservação da qualidade de suas águas superficiais. Essa 
proposta é corroborada pelos respectivos Planos de Bacias, além de outros instrumentos de planejamento já disponíveis (AGEVAP, 2007).

A ampliação do acesso da população ao saneamento básico visando a universalização dos sistemas de saneamento é um dos pontos chave da Lei nº11.445/07 (BRASIL, 2007). 0 PLANSAB foi o instrumento adotado para implementação da PNSB, se apoiando em quatro pilares básicos, abordados de maneira integrada: abastecimento de água potável, esgotamento sanitário, manejo de resíduos sólidos e drenagem das águas pluviais urbanas. Dispondo de metas de curto, médio e longo prazo, considerando as especificidades e distinguindo as regiões do país e ainda as áreas rurais das áreas urbanas, o PNSB possui como metas que até 2033 100\% da população venha a ter abastecimento de água potável e coleta de lixo, além de 87\% de todo esgoto gerado sendo adequadamente disposto (e 93\% deste sendo tratado).

Todavia, passados cerca de 10 anos da LNSB e 4 anos do PLANSAB, os avanços são tímidos perante o tamanho do desafio e boa parte da população brasileira continua ainda sem acesso ao saneamento básico adequado e os números apresentados por diversas fontes (ITB, 2017; CNI, 2016) se situam ainda bem distantes das metas estabelecidas pelo PLANSAB (Ministério das Cidades, 2013) e apesar de alguns avanços constatados eles se demonstram muito lentos em relação às demandas discriminadas pela PNSB no que se refere à universalização do saneamento no país (CNI, 2016; FIRJAN, 2017). Ainda segundo o estudo de RANGEL (2016), tomando como base os municípios do RJ, podem ser constatadas grande incompatibilidade e defasagem entre os investimentos necessários no caminho para a universalização do saneamento e os recursos alocados por esses municípios nos seus respectivos planos plurianuais e demais dotações orçamentárias. 0 ITB (2017) sustenta que além da falta de vontade política em resolver o problema de saneamento, a ociosidade das redes de esgoto também se soma aos tradicionais empecilhos que travam universalização do esgotamento sanitário no país.

Entre os desdobramentos da busca pelo aperfeiçoamento do modelo de gestão atual, alguns instrumentos de planejamento importantes foram implementados nos últimos anos, tais como o Sistema Nacional de Informação sobre Saneamento Básico (SNIS) e os Planos Municipais de Saneamento Básico, compondo um arcabouço que vem sendo criado no sentido de se avançar com necessária universalização do saneamento no país (0BRACZKA et al, 2017; RANGEL, 2016). 0 uso de Indicadores vem se popularizando como ferramenta estratégica na avaliação da prestação dos serviços de saneamento, se tornando uma prática crescente, especialmente a partir da Lei Nacional de Saneamento Básico (VON SPERLING e VON SPERLING, 
Emprego de indicadores na avaliação do saneamento - Região Hidrográfica Médio Paraíba do Sul

2013). De acordo com esses autores, trata-se de um novo marco regulatório do setor por ter institucionalizado o uso de indicadores de desempenho, que passaram a integrar o processo de planejamento, regulação e fiscalização dos serviços. Essa metodologia trouxe como impacto positivo a disponibilização de um banco de dados e de índices padronizados relacionados ao Saneamento que são constantemente atualizados. Sua utilização pelos operadores e gestores do setor possui entre suas finalidades planejar e aferir a eficiência dos sistemas de saneamento, além de proporcionar uma maior transparência e permitir o exercício do controle social (OBRACZKA e LEAL, 2016). A utilização criteriosa desses índices pode também servir de suporte no direcionamento de ações e investimentos, visando aumentar o atendimento e a eficiência dos referidos sistemas e, dessa forma, contribuir para atingimento da almejada universalização, objetivo esse que não depende exclusiva e necessariamente da sua ampliação através da construção de novas redes de esgoto (OBRACZKA e LEAL, 2016; OBRACZKA et al, 2017).

A Associação Brasileira de Engenharia Sanitária (ABES) publicou recentemente um estudo (Ranking ABES da Universalização do Saneamento) que avalia Indicadores de Saneamento (a partir da base de dados do SNIS) e Indicadores de saúde pública (base de dados do DATASUS), definindo um ranking para os 231 municípios mais populosos do país (ABES, 2017). A ABES adotou como indicador de saúde as Doenças Relacionadas ao Saneamento Ambiental Inadequado (DRSAI). Ao avaliarem o impacto das deficiências de saneamento sobre a população brasileira e o Sistema Único de Saúde (SUS), verificaram que, em média, as doenças relacionadas ao saneamento ambiental inadequado (DRSAI) foram responsáveis por 13.449 óbitos ao longo do período de 2001 a 2009. Quanto à assistência médica para as DRSAI, foram relatadas mais de 758 mil internações (Amaral, Oliveira e Ramos, 2016).

Entre alguns dos aspectos avaliados, o estudo aponta o estágio em que os municípios se encontram em termos de universalização, apresentando-os em três categorias, na seguinte ordem decrescente em termos de avanço: "Rumo à Universalização", "Compromisso com a Universalização" e "Primeiros Passos para a Universalização". De acordo com o Ranking, apenas 6\% se enquadram na categoria Rumo à Universalização, 18\% estão em Compromisso com a Universalização e 76\% em "Primeiros Passos para a Universalização", o que demonstra o quão distante estamos da universalização (ABES, 2017). Identificou-se ainda que os municípios melhor posicionados no ranking apresentaram menores taxas de internações por DRSAI, enquanto que municípios com as menores pontuações obtiveram taxas maiores de internações e de mortalidade (ABES, 2017). A Tabela 1 a seguir apresenta o ranking abrangendo os 24 
municípios inseridos nas Regiões Hidrográficas do Rio Paraíba do Sul que se encontram no estudo da ABES, sendo 17 pertencentes ao estado do RJ, 4 ao estado de São Paulo e 3 ao estado de Minas Gerais.

Tabela 1 - Municípios que se inserem na Bacia Paraíba do Sul considerados/ranqueados no estudo realizado pela ABES (2017).

\begin{tabular}{|c|c|c|c|}
\hline Municípios & UF & $\begin{array}{c}\text { R. Hidrográfica / C.de } \\
\text { Bacia }\end{array}$ & Classificação no Ranking da ABES \\
\hline Angra dos Reis & RJ & RH I & Primeiros Passos para a universalização \\
\hline Resende & RJ & RH III & Primeiros Passos para a universalização \\
\hline Volta Redonda & RJ & RH III & Primeiros Passos para a universalização \\
\hline Barra Mansa & RJ & RH III & Primeiros Passos para a universalização \\
\hline Niterói & RJ & RH V & Rumo à universalização \\
\hline São Gonçalo & RJ & RH V & Primeiros Passos para a universalização \\
\hline Itaboraí & RJ & RH V & Primeiros Passos para a universalização \\
\hline Duque de Caxias & RJ & RH V & Primeiros Passos para a universalização \\
\hline Mesquita & RJ & RH V & Primeiros Passos para a universalização \\
\hline S. João de Meriti & RJ & RH V & Primeiros Passos para a universalização \\
\hline Nilópolis & RJ & RH V & Primeiros Passos para a universalização \\
\hline Araruama & RJ & RH VI & Compromisso com a universalização \\
\hline Maricá & RJ & RH VI & Primeiros Passos para a universalização \\
\hline Rio das 0stras & RJ & RH VI & Primeiros Passos para a universalização \\
\hline Petrópolis & RJ & RH IV & Primeiros Passos para a universalização \\
\hline C. Goytacazes & RJ & RH IX & Primeiros Passos para a universalização \\
\hline Nova Friburgo & RJ & RH VII & Compromisso com a universalização \\
\hline S.J. dos Campos & SP & CBH Paraíba do Sul & Rumo à universalização \\
\hline Taubaté & SP & CBH Paraíba do Sul & Rumo à universalização \\
\hline Pindamonhangaba & SP & CBH Paraíba do Sul & Compromisso com a universalização \\
\hline Guaratinguetá & SP & CBH Paraíba do Sul & Primeiros Passos para a universalização \\
\hline Juiz de Fora & MG & CBH Preto Paraibuna & Primeiros Passos para a universalização \\
\hline Muriaé & MG & CBH Pomba Muriaé & Primeiros Passos para a universalização \\
\hline Ubá & MG & CBH Pomba Muriaé & Primeiros Passos para a universalização \\
\hline
\end{tabular}

Fonte: ABES (2017), IGAM e INEA.

Três municípios da Bacia do Médio Paraíba do Sul possuem população superior ao número mínimo de corte adotado pelo estudo (100 mil habitantes), tendo sido, portanto abrangidos pelo ranking da ABES: Volta Redonda, Barra Mansa e Resende. Todos apresentam estágios para a universalização considerados como iniciais, ou seja, "Primeiros Passos rumo à Universalização”, de forma similar ao que ocorre com os municípios mineiros (Juiz de Fora, Muriaé e Ubá), enquanto que os municípios paulistas - encabeçados por Pindamonhangaba se encontram em estágios mais avançados, com exceção de Guaratinguetá (ABES, 2017).

\section{Considerações sobre a bacia adotada como objeto do presente estudo}

Segundo HONJI et al(2017), a bacia do rio Paraíba do Sul possui uma área de 57 mil km² abrangendo os estados de São Paulo (SP) (38\%), Rio de Janeiro (RJ) (38\%) e Minas Gerais (MG) 
Emprego de indicadores na avaliação do saneamento - Região Hidrográfica Médio Paraíba do Sul

(24\%) (HILSDORF e PETRERE, 2002). Sua extensão lhe assegura a posição de segunda maior bacia do leste brasileiro (P0LAZ et al., 2011). 0 seu principal rio é o Paraíba do Sul, com cerca de $1.000 \mathrm{~km}$ de extensão, considerado o maior rio de várzeas do Sudeste (HILSDORF e PETRERE, 2002). 0 Paraíba do Sul, rio de competência federal, abastece as principais capitais e regiões metropolitanas em território nacional (SEBRAE, 2015).

Segundo o INEA, considerando a divisão proposta pelo CERHI-RJ, na Bacia do rio Paraíba do Sul, em território do estado do RJ, estão compreendidas as Regiões Hidrográficas do Médio Paraíba (RH III), Piabanha (RH IV), Rio Dois Rios (RH VII) e Baixo Paraíba do Sul e Itabapoana (RH IX) (INEA).

Essa pesquisa privilegia a Bacia do Médio Paraíba do Sul por se tratar de uma das mais importantes no cenário regional/nacional. Se insere em uma macrorregião responsável por boa parte do Produto Interno Bruto (PIB) do país, concentrando tanto boa parte da atividade econômica nacional como parcela considerável da população brasileira (IBGE, 2011). Nela o uso múltiplo (e estratégico) da água se encontra bem caracterizado, como na geração de energia elétrica, movimentando parte das atividades humanas e econômicas nessa região e também viabilizando o abastecimento de água da maior parte da população da RMRJ. Segundo o CEIVAP (2016), é nessa RH que se localiza a estratégica transposição das águas da bacia do rio Paraíba do Sul para a bacia do rio Guandu, através da Estação Elevatória de Santa Cecília, em Barra do Piraí, que atende tanto ao Sistema Light, gerando energia elétrica, bem como ao sistema CEDAE, fornecendo água para o abastecimento de cerca de 9 milhões de pessoas da Região Metropolitana do Rio de Janeiro através do Sistema Guandu.

Palco de uma série de conflitos pelo uso da água, que extrapolam inclusive os limites interestaduais, essa bacia é também caracterizada pela intensa poluição de suas águas provocadas pelas atividades antrópica que, mesmo dependendo diretamente dessas águas, contribuem paradoxalmente para a degradação ambiental e piora da qualidade desses corpos hídricos. De acordo com o INEA, as principais práticas econômicas da região são as atividades industriais e agropecuárias, além do turismo. Segundo o mesmo portal, destaca-se a formação do segundo maior parque industrial da bacia do rio Paraíba do Sul, com a Companhia Siderúrgica Nacional (CSN), em Volta Redonda.

De acordo com a Resolução nº 18/2006 do Conselho Estadual de Recursos Hídricos (CERHI), a Região Hidrográfica do Médio Paraíba do Sul compreende de forma integral os Municípios fluminenses de Itatiaia, Resende, Porto Real, Quatis, Barra Mansa, Volta Redonda, Pinheiral, Valença, Rio das Flores, Comendador Levy Gasparian e, parcialmente, os Municípios 
de Rio Claro, Piraí, Barra do Piraí, Vassouras, Miguel Pereira, Paty do Alferes, Paraíba do Sul, Três Rios e Mendes, abrangendo uma área total de drenagem de $6.517 \mathrm{~km}^{2}$ (CBH MÉDI0 PARAÍBA DO SUL, 2011).

Segundo o Relatório de Gestão elaborado pelo Comitê Médio Paraíba do Sul (2014), essa sub-bacia possui os melhores percentuais de cobertura florestal e de extensão de florestas de toda a bacia do rio Paraíba do Sul. Porém, em suas áreas urbanas são constatados diversos processos erosivos de relevância ocasionados pela falta de preservação e conservação do solo, sendo carentes de sistemas de esgotamento sanitário e de aterros sanitários adequados. Em conjunto com a forte presença de atividades industriais, há deste modo um favorecimento a degradação ambiental e da qualidade de sua água (CBH MÉDI0 PARAÍBA DO SUL, 2011). Segundo KELMAN, dos $110 \mathrm{~m}^{3}$ /s que chegam à barragem de Santa Cecília, coração do Sistema Guandu, a CEDAE distribui apenas $48 \mathrm{~m}^{3} / \mathrm{s}$ para abastecer residências e indústrias, o que significa que cerca de 50\% da vazão não são efetivamente utilizados, perdendo-se por causa do excesso de poluição, especialmente de esgoto, nela presente (0 GLOB0, 2014).

0 estudo de HONJI et al. (2017) destaca esse problema da poluição hídrica (efluentes domésticos): apesar da bacia do rio Paraíba do Sul possuir índices de coleta de esgotos acima de 90\% (no estado de SP), constata-se que o índice de tratamento ainda se situa em torno de 60\% (São Paulo, 2013/2014). Já no que se refere aos efluentes industriais, deve-se destacar que esta bacia merece especial atenção devido à ação antrópica causada pela instalação da Companhia Siderúrgica Nacional de Volta Redonda (HONJI et al., 2017).

A necessidade de melhoria da situação atual não somente quanto à disponibilidade, mas especialmente em relação à qualidade da água é expressa pela importância a ela atribuída pelo sistema de gestão e planejamento da bacia, no qual vários quesitos apresentados como ações prioritárias refletem direta ou indiretamente tal preocupação. De acordo com as prioridades definidas pelo Caderno de Ações na Área de Atuação da AMPAS (Associação de Usuários das Águas do Médio Paraíba do Sul), referente ao Plano de Recursos Hídricos da Bacia do Rio Paraíba do Sul (AGEVAP, 2007), as ações/programas para melhoria quali-quantitativa dos recursos hídricos são agrupadas em sete recortes temáticos: Redução de cargas poluidoras; Aproveitamento e racionalização de uso dos recursos hídricos; Drenagem urbana e controle de cheias; Planejamento de recursos hídricos; Projetos para ampliação da base de dados e informações; Plano de proteção de mananciais e sustentabilidade no uso do solo; e Ferramentas de construção da gestão participativa. 
Emprego de indicadores na avaliação do saneamento - Região Hidrográfica Médio Paraíba do Sul

Outro importante instrumento de planejamento e gestão disponível é o monitoramento de parâmetros e o estabelecimento de índices de qualidade de água dos corpos hídricos que, no caso do Rio de Janeiro, são de competência do INEA. Segundo o INEA (2016), o monitoramento sistemático e contínuo da qualidade dos principais corpos de água doce fluminenses fornece informações necessárias para a avaliação das águas e o manejo adequado dos ecossistemas aquáticos bem como para a produção de documentos sobre as condições dos corpos hídricos, possibilitando melhor compreensão do ambiente e eficaz alocação de investimentos e ações. Esses dados apresentam um retrato da qualidade dos rios por meio da aplicação do Índice de Qualidade de Água (IQANSF), que consolida em um único valor os resultados de parâmetros como DBO, DQO, OD e outros (INEA, 2016).

\section{MATERIAL E MÉTODOS}

A etapa inicial foi composta por pesquisa bibliográfica e documental. Foram levantados estudos e referências sobre o tema e sobre a região/bacia objeto da pesquisa, além de informações dos bancos de dados do SNIS e do DATASUS/IBGE. Em sequência, o presente estudo se baseou na metodologia empregada pelo estudo da ABES (2017) que correlaciona indicadores de saneamento do SNIS a indicadores de saúde (baseados em dados do DATASUS). Estes últimos são baseados no número de notificações de internações/mortalidade relacionadas à categoria feco-oral das Doenças DRSAI, por serem dentre todas essas doenças aquelas de maior incidência no período de 2000 a 2013 (IBGE, 2017). Neste trabalho foram considerados os mesmos cinco indicadores e as taxas referentes às DRSAI do estudo da ABES (ABES, 2017), bem como as respectivas metodologias de cálculo, para a análise e "ranqueamento" em relação ao estágio quanto à universalização do saneamento dos 18 municípios que integram a bacia do Médio Paraíba do Sul. Os cinco indicadores de saneamento adotados são: abastecimento de água, coleta de esgoto, tratamento de esgoto, coleta de lixo e destinação adequada de resíduos sólidos. As informações básicas para a composição/cálculo dos indicadores de saneamento são apresentadas a seguir (Tabela 2).

Tabela 2: Características dos Indicadores de saneamento adotados

\begin{tabular}{|l|l|c|l|}
\hline \multicolumn{1}{|c|}{ Indicador } & \multicolumn{1}{c|}{ Descrição } & Fonte & \multicolumn{1}{c|}{ Forma de cálculo } \\
\hline $\begin{array}{l}\text { Abastecimento } \\
\text { de Água }\end{array}$ & $\begin{array}{l}\text { Índice de atendimento } \\
\text { da população total com } \\
\text { rede de água }\end{array}$ & $\begin{array}{c}\text { SNIS, } \\
\text { IN055_AE }\end{array}$ & $\begin{array}{l}\text { (População total atendida } \\
\text { com abastecimento de água/População } \\
\text { total residente do(s) município(s) com } \\
\text { abastecimento de água(IBGE) X 100 }\end{array}$ \\
\hline
\end{tabular}




\begin{tabular}{|c|c|c|c|}
\hline Coleta de Esgoto & $\begin{array}{l}\text { Índice de atendimento } \\
\text { da população total com } \\
\text { rede de esgotos }\end{array}$ & $\begin{array}{c}\text { SNIS, } \\
\text { IN056_AE }\end{array}$ & $\begin{array}{l}\text { (População total atendida com } \\
\text { esgotamento sanitário/População total } \\
\text { residente do(s) município(s) com } \\
\text { abastecimento de água, } \\
\text { segundo o IBGE) X } 100\end{array}$ \\
\hline $\begin{array}{l}\text { Tratamento de } \\
\text { Esgoto }\end{array}$ & $\begin{array}{l}\text { Índice de esgoto } \\
\text { tratado } \\
\text { referido à água } \\
\text { consumida }\end{array}$ & $\begin{array}{c}\text { SNIS, } \\
\text { IN046_AE }\end{array}$ & $\begin{array}{l}\text { ((Volume de esgotos tratado + Volume de } \\
\text { esgoto bruto exportado } \\
\text { tratado nas instalações do importador) / } \\
\text { (Volume de água consumido - Volume de } \\
\text { água tratada exportado)) X } 100\end{array}$ \\
\hline Coleta de Lixo & $\begin{array}{l}\text { Taxa de cobertura do } \\
\text { serviço de coleta de } \\
\text { resíduos sólidos } \\
\text { domiciliares em relação } \\
\text { à população total do } \\
\text { município }\end{array}$ & $\begin{array}{c}\text { SNIS, } \\
\text { IN015_RS }\end{array}$ & $\begin{array}{l}\text { (População total atendida no município / } \\
\text { População total do } \\
\text { município - Fonte: IBGE) X } 100\end{array}$ \\
\hline $\begin{array}{l}\text { Destinação } \\
\text { Adequada de } \\
\text { resíduos sólidos }\end{array}$ & $\begin{array}{l}\text { Percentual de resíduos } \\
\text { sólidos domésticos } \\
\text { (RD0) e públicos (RPU) } \\
\text { gerados pelo município } \\
\text { destinados } \\
\text { adequadamente }\end{array}$ & $\begin{array}{l}\text { SNIS, UP007; } \\
\text { UP025; } \\
\text { UP003 }\end{array}$ & $\begin{array}{l}\text { (Total de RD0 e RPU destinados para } \\
\text { unidades de processamento consideradas } \\
\text { adequadas / Total de RD0 e RPU } \\
\text { produzidos pelo município de origem) X } \\
100\end{array}$ \\
\hline
\end{tabular}

Fonte: ABES, 2017

A classificação se baseou nas Faixas de Pontuação e respectivas Categorias também estabelecidas pelo estudo da ABES (Tabela 3).

Tabela 3 - Categorias definidas pelo estudo da ABES e respectivas faixas de pontuação

\begin{tabular}{|l|c|}
\hline \multicolumn{1}{|c|}{ Categoria } & Faixas de Pontuação \\
\hline Rumo à universalização & Acima de 489 \\
\hline Compromisso com a universalização & $450-489$ \\
\hline Primeiros Passos para a universalização & Abaixo de 450 \\
\hline
\end{tabular}

Fonte: ABES, 2017

As doenças DRSAI adotadas são da Categoria Transmissão feco-oral e os grupos de doenças são as Diarreias, Febre Entérica e a Hepatite A (Tabela 4).

Tabela 4: Doenças Relacionadas ao Saneamento Básico Inadequado (DRSAI) da Categoria e Transmissão Feco-oral

\begin{tabular}{|c|c|c|c|}
\hline Categoria & $\begin{array}{l}\text { Grupo de } \\
\text { Doenças }\end{array}$ & Doenças & CID - 10 \\
\hline $\begin{array}{l}\text { Transmissão } \\
\text { feco-oral }\end{array}$ & 1. Diarreias & $\begin{array}{l}\text { 1.1 Cólera } \\
1.2 \text { Infecções por Salmonella } \\
\text { 1.3 Shingelose } \\
\text { 1.4 Outras infecções intestinais bacterianas } \\
\text { (Escherichia coli, Compylobacter, Yersinia } \\
\text { enterocolitica, Clastridium difficile, outras e as não } \\
\text { especificadas) } \\
\text { 1.5 Amebíase }\end{array}$ & $\begin{array}{l}\mathrm{A} 00 \\
\mathrm{~A} 02 \\
\mathrm{~A} 03\end{array}$ \\
\hline
\end{tabular}



Sul

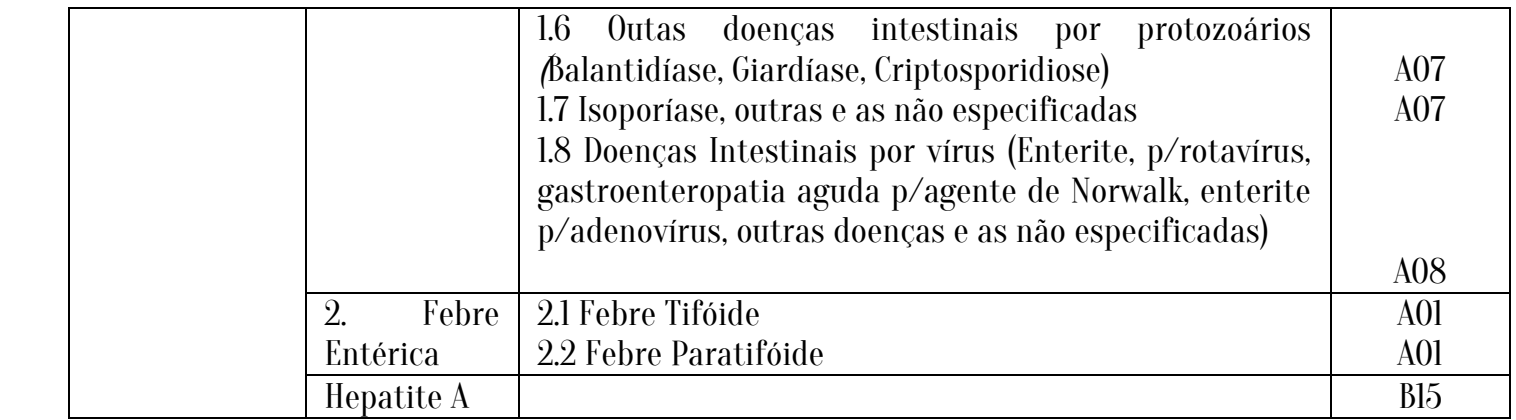

Fonte: ABES, 2017

No estudo/relatório elaborado pela ABES (2017), os indicadores de saúde foram calculados a partir do número de internações por DRSAI de toda a categoria de transmissão feco-orais, exceto Hepatite A.

No presente estudo, porém, pela dificuldade de se obter certos dados específicos para todos os municípios envolvidos na pesquisa, as informações necessárias referentes aos indicadores de saúde foram obtidas através do banco de dados do IBGE, a partir do número de casos de internações somente pelas diarreias, para cada município. Essa simplificação foi considerada plausível uma vez que as diarreias englobam a maior parte dessas doenças (Tabela 4) e também por predominar fortemente em termos de incidência em toda a Categoria de Transmissão feco-oral. Assim, adotou-se a taxa de Diarreias como a de toda a Categoria de Transmissão feco-oral referente às DRSAI.

\section{RESULTADOS E DISCUSSÃ0}

A Tabela 5 apresenta os resultados obtidos para os municípios integrantes da Região Hidrográfica do Médio Paraíba do Sul, para os cinco indicadores de saneamento considerados. Em casos onde pela indisponibilidade dos dados necessários não foi possível definir a pontuação de um determinado indicador para alguns dos sistemas de saneamento municipais, foram então considerados os valores mínimo (0\%) e máximo (100\%) possíveis para esse indicador é adotada uma faixa de pontuação total, possibilitando a inserção de todos os municípios no "ranking" e a análise dos resultados possíveis. Sendo assim, foram feitos dois possíveis Ranking, considerando a pontuação mínima e máxima possível respectivamente. É possível perceber que, dentre os cinco indicadores, o abastecimento de água é o que obtém as melhores porcentagens de atendimento, situando-se abaixo de 90\% somente em três municípios. Já o indicador de tratamento de esgoto é aquele que apresenta os piores 
resultados: nove municípios - 50\% do total - sequer oferecem tal serviço (considerando os valores mínimos para os municípios com dados indisponíveis).

Tabela 5: Resultados obtidos para os indicadores de saneamento dos municípios da RH III (em \% e de acordo com dados de 2015) e respectivas pontuações e posição no ranking de acordo com ABES (2017).

\begin{tabular}{|c|c|c|c|c|c|c|c|c|}
\hline $\begin{array}{l}\text { Municípios } \\
\text { UF }\end{array}$ & $\begin{array}{l}\text { Abast. } \\
\text { de Água }\end{array}$ & $\begin{array}{l}\text { Coleta de } \\
\text { Esgoto }\end{array}$ & $\begin{array}{l}\text { Trat. de } \\
\text { Esgoto }\end{array}$ & $\begin{array}{l}\text { Coleta } \\
\text { de Lixo }\end{array}$ & $\begin{array}{l}\text { Destinação } \\
\text { Adequada } \\
\text { RSU }\end{array}$ & $\begin{array}{l}\text { Pontuação } \\
\text { Total }\end{array}$ & $\begin{array}{l}\text { Posição } \\
\text { Rankingl }\end{array}$ & $\begin{array}{l}\text { Posição } \\
\text { Ranking2 }\end{array}$ \\
\hline Itatiaia RJ & 95,40 & 62,50 & 0 & 96,63 & $X(0$ ou 100$)$ & $\begin{array}{c}254,53 \mathrm{a} \\
354,53\end{array}$ & $16^{\circ}$ & $12^{\circ}$ \\
\hline Resende RJ & 95,55 & 95,34 & 62,0 & 99,92 & 0 & 353,0 & $8^{\circ}$ & $13^{\circ}$ \\
\hline $\begin{array}{ll}\text { Porto } & \text { Real }^{3} \\
\text { RJ } & \end{array}$ & 97,8 & 96,8 & 33,40 & 100,0 & 100 & 428,0 & $2^{0}$ & $4^{0}$ \\
\hline Quatis ${ }^{3}$ RJ & 100,0 & 100,0 & 60,0 & 100,0 & 100 & 460,0 & $1^{0}$ & $1^{0}$ \\
\hline $\begin{array}{l}\text { Barra Mansa } \\
\text { RJ }\end{array}$ & 97,98 & 89,07 & 3,06 & 99,70 & 100 & 390,0 & $6^{0}$ & $9^{\circ}$ \\
\hline $\begin{array}{l}\text { Volta } \\
\text { Redonda RJ }\end{array}$ & 99,95 & 98,96 & 19,32 & 100,0 & 100 & 418,0 & $3^{\circ}$ & $5^{0}$ \\
\hline Pinheiral $^{4}$ RJ & 90,2 & 100,0 & 0 & 100,0 & 100 & 390,2 & $5^{0}$ & $8^{\circ}$ \\
\hline Valença RJ & 90,3 & 40,1 & 0 & 100,0 & 0 & 230,4 & $17^{\circ}$ & $18^{\circ}$ \\
\hline $\begin{array}{l}\text { Rio das } \\
\text { Flores RJ }\end{array}$ & 69,6 & 69,6 & 65,27 & 69,6 & 0 & 274,07 & $14^{\circ}$ & $17^{\circ}$ \\
\hline $\begin{array}{ll}\text { Com. } & \text { L. } \\
\text { Gasparian } & \\
\text { RJ } & \\
\end{array}$ & 99,7 & 99,7 & 0 & 100,0 & $X(0$ ou 100$)$ & $\begin{array}{c}299,4 \text { a } \\
399,4\end{array}$ & $12^{\circ}$ & $6^{0}$ \\
\hline Rio Claro 3 RJ & $\begin{array}{c}X(0 \text { ou } \\
100)\end{array}$ & 65,0 & $\begin{array}{c}\mathrm{X}(0 \text { ou } \\
100)\end{array}$ & 100,0 & 100 & $\begin{array}{c}265,0 \text { a } \\
465,0\end{array}$ & $15^{\circ}$ & $2^{o}$ \\
\hline $\begin{array}{ll}\text { Barra } & \text { do } \\
\text { Piraí RJ } & \\
\end{array}$ & 100,0 & 96,7 & 0,0 & 98,78 & 100 & 395,48 & $4^{0}$ & $7^{0}$ \\
\hline $\begin{array}{l}\text { Vassouras } \\
\text { RJ }\end{array}$ & 95,3 & 53,3 & 3,8 & 90,0 & 100 & 342,4 & $9^{\circ}$ & $14^{\circ}$ \\
\hline $\begin{array}{l}\text { Miguel } \\
\text { Pereira RJ }\end{array}$ & 99,9 & 45,49 & 27,5 & 100,0 & 100 & 372,89 & $7^{\circ}$ & $11^{\circ}$ \\
\hline $\begin{array}{l}\text { Paty do } \\
\text { Alferes RJ }\end{array}$ & 72,5 & 65,11 & 0 & 90,61 & $X(0$ ou 100$)$ & $\begin{array}{c}228,22 \text { a } \\
328,22 \\
\end{array}$ & $18^{\circ}$ & $15^{\circ}$ \\
\hline $\begin{array}{l}\text { Paraíba do } \\
\text { Sul RJ }\end{array}$ & 95,0 & 81,6 & 0 & 100,0 & $X(0$ ou 100$)$ & $\begin{array}{c}276,6 \text { a } \\
376,6 \\
\end{array}$ & $13^{\circ}$ & $10^{\circ}$ \\
\hline Três Rios RJ & 100,0 & 99,0 & 4,4 & 100,0 & 0 & 303,4 & $11^{\circ}$ & $16^{0}$ \\
\hline Mendes RJ & 80,0 & 61,3 & $\begin{array}{c}\mathrm{X}(0 \text { ou } \\
100)\end{array}$ & 100,0 & 100 & $\begin{array}{c}341,3 \text { a } \\
441,3 \\
\end{array}$ & $10^{\circ}$ & $3^{\circ}$ \\
\hline \multicolumn{9}{|c|}{ Municípios de outros estados, na Bacia do Paraíba do Sul, contemplados no estudo da ABES (2017) } \\
\hline Taubaté SP & 100,0 & 96,58 & 94,7 & 100,0 & 100 & 491,28 & - & - \\
\hline $\begin{array}{l}\text { Pindamo } \\
\text { nhangaba } \\
\text { SP } \\
\end{array}$ & 100,0 & 96,69 & 78,65 & 100,0 & 100 & 475,34 & - & - \\
\hline $\begin{array}{l}\text { Juiz de Fora } \\
\text { MG }\end{array}$ & 95,84 & 94,73 & 6,08 & 99,68 & 100 & 396,33 & - & - \\
\hline Muriaé MG & 100,0 & 100,0 & 29,01 & 100,0 & 100 & 429,01 & - & - \\
\hline
\end{tabular}

(1) De acordo com a Pontuação mínima possível. (2) De acordo com a Pontuação máxima possível.

Fonte: SNIS, 2015. 
Emprego de indicadores na avaliação do saneamento - Região Hidrográfica Médio Paraíba do Sul

No cálculo do indicador de Destinação Final Adequada, considerou-se que os municípios de Rio Claro, Quatis e Porto Real destinam seus resíduos no Aterro de Barra Mansa, segundo dados fornecidos pelo SNIS, enquanto que os resíduos de Pinheiral são aterrados no CTR Barra Mansa, de acordo com dados disponibilizados pela empresa FOXX HAZTEC (http://www.haztec.com.br).

Com exceção de Paty do Alferes, Mendes e Rio das Flores, todos os demais municípios representando 95\% da população total - apresentam índice de abastecimento de água superior a 90\%. Mesmo se for considerada a meta para o indicador Al do PLANSAB para 2018 (98\% de abastecimento de domicílios urbanos e rurais por rede, poço ou nascente), cerca de $70 \%$ da população total já se encontra atendida. A coleta de resíduos também apresenta bom desempenho, uma vez que somente o município de Rio das Flores - que representa menos do que $1 \%$ da população total - apresenta indicador inferior a 90\%. Já a coleta de esgoto apresenta um desempenho intermediário. Cerca de $60 \%$ da população se encontra atendida de acordo com a meta do PLANSAB projetada para esse indicador em 2018 (90\% de coleta ou fossa para domicílios urbanos e rurais). 0 pior indicador é indubitavelmente o que se refere ao Tratamento de esgotos, uma vez que 55\% da população total não têm praticamente acesso a esse serviço, incluindo municípios importantes como Paraíba do Sul, Três Rios, Barra do Piraí, Valença e Barra Mansa. Atendendo a meta do PLANSAB para 2018 (63\% de tratamento do esgoto coletado) somente podem ser contabilizados os municípios de Rio das Flores e Resende, que representam apenas $12 \%$ da população total avaliada.

A Tabela 6, a seguir, apresenta as pontuações totais para o somatório dos indicadores de saneamento e as taxas referentes às DRSAI para os municípios do Médio Paraíba, além da respectiva classificação por Categoria, de acordo com ABES (2017). Adotou-se como base a pontuação total obtida na Tabela 5. 0 Ranking foi baseado na taxa de DRSAI e em caso de empate, utilizou-se a pontuação obtida no saneamento.

Tabela 6: Pontuação Total obtida pelos indicadores, taxas de internações por município e respectiva categoria no ranking ABES

\begin{tabular}{l|c|c|c|c|c}
\hline $\begin{array}{c}\text { Municípios } \\
\text { UF }\end{array}$ & População & $\begin{array}{c}\text { Pontuação } \\
\text { Total } \\
\text { Saneamento }\end{array}$ & Categoria $^{1}$ & $\begin{array}{c}\text { DRSAI } \\
\text { Internações } \\
\text { por 105hab }\end{array}$ & Ranking \\
\hline Itatiaia RJ & 28.783 & $\begin{array}{c}254,53 \text { a } \\
354,53\end{array}$ & $\begin{array}{c}\text { Primeiros passos para a } \\
\text { universalização }\end{array}$ & 0,2 & $7^{\circ}$ \\
\hline Resende RJ & 119.769 & 353,0 & $\begin{array}{c}\text { Primeiros passos para a } \\
\text { universalização }\end{array}$ & 0,3 & $8^{\circ}$ \\
\hline $\begin{array}{l}\text { Porto Real } \\
\text { RJ }\end{array}$ & 16.592 & 428,0 & $\begin{array}{c}\text { Primeiros passos para a } \\
\text { universalização }\end{array}$ & 0,1 & $1^{\circ}$ \\
\hline
\end{tabular}




\begin{tabular}{|c|c|c|c|c|c|}
\hline Quatis RJ & 12.793 & 460,0 & $\begin{array}{c}\text { Compromisso com a } \\
\text { universalização }\end{array}$ & 2,0 & $17^{\circ}$ \\
\hline $\begin{array}{l}\text { Barra Mansa } \\
\text { RJ }\end{array}$ & 177.813 & 390,0 & $\begin{array}{c}\text { Primeiros passos para a } \\
\text { universalização }\end{array}$ & 0,1 & $3^{\circ}$ \\
\hline $\begin{array}{l}\text { Volta } \\
\text { Redonda RJ }\end{array}$ & 257.803 & 418,0 & $\begin{array}{c}\text { Primeiros passos para a } \\
\text { universalização }\end{array}$ & 0,1 & $2^{o}$ \\
\hline Pinheiral RJ & 22.719 & 390,2 & $\begin{array}{c}\text { Primeiros passos para a } \\
\text { universalização }\end{array}$ & 0,2 & $5^{0}$ \\
\hline Valença RJ & 71.843 & 230,4 & $\begin{array}{c}\text { Primeiros passos para a } \\
\text { universalização }\end{array}$ & 1,1 & $14^{\circ}$ \\
\hline $\begin{array}{l}\text { Rio das } \\
\text { Flores RJ }\end{array}$ & 8.561 & 274,07 & $\begin{array}{c}\text { Primeiros passos para a } \\
\text { universalização }\end{array}$ & 1,0 & $12^{\circ}$ \\
\hline $\begin{array}{ll}\text { C. } & \text { L. } \\
\text { Gasparian } \\
\text { RJ }\end{array}$ & 8.180 & 299,4 a 399,4 & $\begin{array}{c}\text { Primeiros passos para a } \\
\text { universalização }\end{array}$ & Não fornecido & - \\
\hline Rio Claro RJ & 17.425 & 265,0 a 465,0 & $\begin{array}{c}\text { Primeiros passos para a } \\
\text { universalização }\end{array}$ & 0,1 & $4^{0}$ \\
\hline $\begin{array}{ll}\text { Barra } & \text { do } \\
\text { Piraí RJ } & \\
\end{array}$ & 94.778 & 395,48 & $\begin{array}{c}\text { Primeiros passos para a } \\
\text { universalização }\end{array}$ & 1,9 & $16^{\circ}$ \\
\hline $\begin{array}{l}\text { Vassouras } \\
\text { RJ }\end{array}$ & 34.410 & 342,4 & $\begin{array}{c}\text { Primeiros passos para a } \\
\text { universalização }\end{array}$ & 0,2 & $6^{0}$ \\
\hline $\begin{array}{l}\text { Miguel } \\
\text { Pereira RJ }\end{array}$ & 24.642 & 372,89 & $\begin{array}{c}\text { Primeiros passos para a } \\
\text { universalização }\end{array}$ & 1,3 & $15^{\circ}$ \\
\hline $\begin{array}{l}\text { Paty do } \\
\text { Alferes RJ }\end{array}$ & 26.359 & $\begin{array}{c}228,22 \text { a } \\
328,22\end{array}$ & $\begin{array}{c}\text { Primeiros passos para a } \\
\text { universalização }\end{array}$ & 0,8 & $11^{\circ}$ \\
\hline $\begin{array}{l}\text { Paraíba do } \\
\text { Sul RJ }\end{array}$ & 41.084 & 276,6 а 376,6 & $\begin{array}{c}\text { Primeiros passos para a } \\
\text { universalização } \\
\end{array}$ & 0,3 & $10^{\circ}$ \\
\hline Três Rios RJ & 77.432 & 303,4 & $\begin{array}{c}\text { Primeiros passos para a } \\
\text { universalização } \\
\end{array}$ & 1,1 & $13^{\circ}$ \\
\hline Mendes RJ & 17.935 & 341,3 а 441,3 & $\begin{array}{c}\text { Primeiros passos para a } \\
\text { universalização }\end{array}$ & 0,3 & $9^{\circ}$ \\
\hline
\end{tabular}

\begin{tabular}{l|c|c|c|c|c}
\hline \multicolumn{7}{l}{ Municípios de outros estados na B. do Paraíba do Sul contemplados no estudo da ABES (2017) } \\
\hline Taubaté SP & 278.686 & 491,28 & Rumo à universalização & 0 & - \\
\hline $\begin{array}{l}\text { Pindamo } \\
\text { nhangaba }\end{array}$ & 146.955 & 475,34 & $\begin{array}{c}\text { Compromisso com a } \\
\text { universalização }\end{array}$ & 0,2 & - \\
SP & 516.247 & 396,33 & $\begin{array}{c}\text { Primeiros passos para a } \\
\text { universalização }\end{array}$ & 0,5 & - \\
\hline $\begin{array}{l}\text { Juiz de Fora } \\
\text { MG }\end{array}$ & 100.765 & 429,01 & $\begin{array}{c}\text { Primeiros passos para a } \\
\text { universalização }\end{array}$ & 1,1 & - \\
\hline Muriaé MG
\end{tabular}

(1) Categoria definida pelo estudo (ranking) da ABES para posicionar os Municípios quanto à universalização da água.

Fonte: Adaptado de ABES (2017).

Os resultados dos indicadores indicam que há uma defasagem considerável em termos de saneamento entre os municípios fluminenses da bacia do Médio Paraíba, embora quase todos eles se encontrem no estágio inicial em relação à universalização do saneamento (“Primeiros passos para a universalização”), de acordo com a classificação estabelecida pela ABES (2017). Dos 18 municípios avaliados, somente Quatis se insere no estágio intermediário, o de "Compromisso com a universalização", muito embora apresente resultado muito desfavorável sob a ótica de indicadores de saúde. Mesmo quando adotados valores os mais 
Emprego de indicadores na avaliação do saneamento - Região Hidrográfica Médio Paraíba do Sul

otimistas possíveis (100\%) para os índices de saneamento nos municípios onde não se dispõe de dados sobre alguns indicadores, o panorama geral pouco se altera: somente o município de Rio Claro passaria do estágio de "Primeiros passos para a universalização" ao de "Compromisso com a universalização", representando - em conjunto com Quatis - somente 3\% da população total dos municípios fluminenses avaliados.

Paradoxalmente, municípios de maior porte e/ou pujança econômica como Itatiaia, Resende, Três Rios, Paraíba do Sul e Valença se situam no grupo intermediário ou mesmo mais “atrasado" em relação à universalização, lembrando que são justamente esses, em termos proporcionais, que geram mais rejeitos líquidos e sólidos na bacia estudada. A única exceção é Volta Redonda, município mais populoso entre os casos avaliados. Por outro lado, constata-se que entre os cinco municípios melhores situados no ranking de saneamento, três podem ser considerados como de menor porte, possuindo população inferior a 25 mil habitantes (Quatis, Porto Real e Pinheiral). Podem ser constatados ainda casos de municípios com pontuação/desempenho muito abaixo dos seus pares, como Paty do Alferes, Rio Claro e Valença, sendo inclusive esse último um dos mais populosos da bacia estudada.

Os indicadores referentes ao "Tratamento de Esgotos" são os que no geral apresentam piores índices enquanto que os melhores se concentram em "Abastecimento de Água”, o que corrobora os dados levantados nas referências inicialmente consultadas. A análise desses índices aponta para a existência de um problema crônico e cíclico de causa e efeito, a partir de uma maior oferta de água a população, mas por outro lado não havendo a disponibilização de uma infraestrutura adequada de esgotamento sanitário, especialmente a de tratamento de efluentes, com consequências nocivas para a qualidade dos corpos hídricos locais.

Especificamente no que diz respeito aos Resíduos Sólidos, como os municípios priorizam a coleta de lixo, o respectivo indicador apresenta desempenho muito melhor do que Destinação Adequada.

No que se refere aos indicadores de saúde, Porto Real, Barra Mansa, Rio Claro e Volta Redonda apresentam os melhores índices de taxa de internações por DRSAI $(0,1)$. 65\% da população dos municípios avaliados podem ser contabilizadas abaixo de 0,5 internações por $10^{5}$ habitantes. Já municípios importantes como Valença, Barra do Pirai e Três Rios representando $25 \%$ do número total de habitantes - são destaques negativos nesse quesito, apresentando taxas de internações por DRSAI superiores a 1,0.

Ao contrário do que ocorreu no estudo da ABES (2017), verifica-se ainda que não se pode estabelecer, a princípio, uma correlação direta entre as pontuações e taxas atribuídas aos 
municípios nos setores de saneamento e saúde, com base nos presentes resultados. Tome-se o exemplo do município de Quatis: é o $1^{0}$ no ranking de saneamento e o $18^{\circ}$ (último) no de taxa de internações por doenças DRSAI, se configurando como o pior desempenho nesse quesito dentre todos os municípios avaliados, junto com Barra do Piraí. Se for considerado o conjunto de índices (saúde e saneamento), os municípios de Porto Real e Volta Redonda merecem ser destacados como exemplos positivos, cabendo a Valença e Três Rios o papel de destaques negativos.

Se comparados às pontuações dos outros municípios ranqueados pela ABES que pertencem a Bacia Paraíba do Sul, localizados em outros estados (Taubaté (SP), Pindamonhangaba (SP), Juiz de Fora (MG) e Muriaé (MG), os 18 municípios da região do Médio Paraíba ora avaliados apresentam piores resultados em termos de indicadores e classificação em estágios de universalização mais atrasados do que esses seus pares utilizados como referência. Somente Quatis, Porto Real e V. Redonda possuem pontuação superior a Juiz de Fora, município que apresenta os piores números entre os quatro não localizados no RJ.

\section{CONCLUSÃO}

A metodologia adotada utiliza o critério de somatório simples de cinco indicadores para cálculo da pontuação, categoria e da posição no ranking de saneamento de cada município, podendo, portanto ser considerada como uma simplificação. Todavia, se configura como uma importante contribuição para gestão dos recursos hídricos, mais especificamente quanto ao objetivo de melhoria da situação do saneamento ambiental da bacia, no geral, e em cada município, em particular. A qualidade de um corpo hídrico não depende somente de uma fonte de poluição, sendo função também da situação de todos os geradores/poluidores situados na mesma bacia de contribuição, o que reforça a importância de uma abordagem sistêmica e integrada. 0 viés comparativo intrínseco ao modelo de análise ora adotado é reforçado pelo paradigma de planejamento por bacia hidrográfica, já consagrada por outros instrumentos de planejamento e gestão de recursos hídricos, inclusive pela "Lei das Águas" (Lei 9433/97).

Pode ser também inferido que aspectos como a não titularidade (de uma maneira geral) dos municípios quanto aos serviços de saneamento - ao contrário do que ocorre com a drenagem e os resíduos sólidos - contribuem para que as carências de saneamento básico se constituam em um problema de equacionamento mais difícil. 
Emprego de indicadores na avaliação do saneamento - Região Hidrográfica Médio Paraíba do Sul

Recomendam-se os seguintes desdobramentos necessários à presente pesquisa: (a) Aprofundamento dos estudos, pesquisando, ratificando ou atualizando os dados que serviram como base na definição dos valores dos indicadores, além de estender essa avaliação para outras bacias hidrográficas; (b) Avaliação de outras fontes de informação, como os Planos Municipais de Saneamento e de Resíduos Sólidos e Planos de Bacia Hidrográfica; (c) Identificação se há previsão ou dotação orçamentária nos Planos Plurianuais dos municípios considerados como mais "atrasados" em termos de estágio de universalização - para solucionar determinado aspecto do saneamento local considerado como prioritário para intervenção. Caso não possuam, podem ser inseridas como prioridades nas intervenções a serem implementadas nas respectivas bacias; e finalmente (d) Análise dos estágios atuais do saneamento em cada município em relação aos objetivos e metas previstos pelo PLANSAB, identificando a titularidade dos serviços de saneamento e apontando ações prioritárias para prosseguimento no caminho rumo à universalização recomendada pela LNSB.

\section{REFERÊNCIAS BIBLIOGRÁFICAS}

ALENCAR, E. Poluição leva a perda de 48,3\% da água que chega ao Guandu. 0 GLOBO, Rio de Janeiro, 24 de nov. de 2014. Disponível em: 〈https://oglobo.globo.com/rio/poluicao-leva-perda-de-483-da-agua-que-chega-ao-guandu14516500>. Acesso em: Abril de 2018.

AMARAL, M.H., OLIVEIRA, L.F. de, e RAMOS, S.B., 2016. Tendência das taxas de internação por Doenças Relacionadas ao Saneamento Ambiental Inadequado (DRSAI): Brasil, 1998 a 2014. Ciência et Praxis v. 9, n. 17, 43-47.

ASSOCIAÇÃO PRÓ-GESTÃo DAS ÁGUAS DA BACIA HIDROGRÁFICA DO RI0 PARAÍBA DO SUL AGEVAP. Plano de Recursos Hídricos da Bacia do Rio Paraíba do Sul - Resumo Plano de Recursos Hídricos Consolidado - Relatório Final.

ASSOCIAÇÃO BRASILEIRA DE ENGENHARIA SANITÁRIA (ABES), 2017. Ranking ABES da Universalização do Saneamento. Disponível em 〈https://www.abesfenasan2017.com.br/Ranking_ABES_universalizacao-dosaneamento.pdf>. Acesso em: Março de 2018.

BRASIL, 2007. Lei $n^{0}$ 11.445/2007. Lei de Nacional de Saneamento Básico - LNSB. Presidência da República. Casa Civil. Subchefia para Assuntos Jurídicos. Disponível em: <http://www.planalto.gov.br/ccivil_03/_ato20072010/2007/lei/l11445.htm>. Acesso em: Março de 2018.

Saneamento e Coleta de Lixo avançam, segundo PNAD. Disponível em: 〈http://www.brasil.gov.br/infraestrutura/2016/11/saneamento-e-coleta-de-lixo-avancam-segundo-pnad . Acesso em: Abril de 2018.

CEIVAP. Situação Atual dos Sistemas de Abastecimento de Água e de Esgotamento Sanitário das Principais Localidades da Bacia do Rio Paraíba do Sul - Rio de Janeiro. Disponível em: <http://www.ceivap.org.br/downloads/Tabela\%20abastecimento\%20RJ.pdf $>$. Acesso em: Março de 2018.

COMITÊ MÉDIO PARAÍBA DO SUL. Relatório de Gestão Hidrográfica do Médio Paraíba do Sul. Disponível em: $<$ http://www.cbhmedioparaiba.org.br/downloads/Relatorio\%20Medio\%20Paraiba\%20do\%20Sul\%20_diagramado_. pdf $>$. Acesso em: Abril de 2018. 
. Área de atuação. Disponível em: 〈http://www.cbhmedioparaiba.org.br/area-atuacao.php〉. Acesso em: Abril de 2018.

CONFEDERAÇÃO NACIONAL DA INDÚSTRIA - CNI, 2016. 0 financiamento do investimento em infraestrutura no Brasil: Uma agenda para sua expansão sustentada. Brasília.

GUIMARÃES, CARVALHO e SILVA, 2007. Saneamento Básico. Disponível em: 〈http://www.ufrrj.br/institutos/it/deng/leonardo/downloads/APOSTILA/Apostila\%20IT\%20179/Cap\%201.pdf〉. Acesso em: Agosto, 2018.

HONGI L.R.M, TOLUSSI, C.E, CANEPPELE D, POLAZ C.N.M,HILSDORF A.W.S, MOREIRA R.G, 2017. Biodiversidade e conservação da ictiofauna ameaçada de extinção da bacia do rio Paraíba do Sul Revista da Biologia 17(2):18-30.

INSTITUTO BRASILEIR0 DE GEOGRAFIA E ESTATÍSTICA - IBGE. 0 Brasil em Síntese. Disponível em: <https://cidades.ibge.gov.br >. Acesso em: Abril de 2018.

Indicadores de desenvolvimento sustentável: Brasil 2015. Rio de Janeiro, 2015. p. 164. Disponível em: 〈https://biblioteca.ibge.gov.br/visualizacao/livros/liv94254_.pdf〉. Acesso em: Abril de 2018.

Dados dos Censos demográficos referentes aos anos de 2000 e 2010. Disponível em: <http://www.ibge.gov.br/home/estatistica/populacao/censo2010/default.shtm〉

<http://www.ibge.gov.br/home/estatistica/populacao/default_censo_2000.shtm〉. Acesso em: Abril de 2018.

INSTITUT0 TRATA BRASIL (ITB), 2017. Ranking do Saneamento. Disponível em: 〈http://www.tratabrasil.org.br/datafiles/estudos/ranking/2017/relatoriocompleto.pdf >. Acesso em: Abril de 2018.

Principais Estatísticas do Brasil. Disponível em: <http://www.tratabrasil.org.br/saneamento/principaisestatisticas-no-brasil >. Acesso em: Abril de 2018.

e EXANTE CONSUlTORIA ECONÔMICA, 2017. Benefícios Econômicos e Sociais da Expansão do Saneamento

no Rio de Janeiro. Disponível em:

<http://www.tratabrasil.org.br/component/estudos/itb/benef\%C3\%ADciosecon\%C3\%B4micos-e-sociais-daexpans\%C3\%A30-do-saneamento-no-rio-de-janeiro/itb>. Acesso em: Abril de 2018.

/REINFRA, 2015. Ociosidade das Redes de Esgotamento Sanitário no Brasil. Disponível:<http://www.tratabrasil.org.br/datafiles/estudos/ociosidade/relatoriocompleto.pdf>. Acesso em: Março de 2018.

INSTITUTO ESTADUAL D0 AMBIENTE (INEA). RH III Região Hidrográfica do Médio Paraíba do Sul. - Disponível em: <http://www.inea.rj.gov.br/Portal/Agendas/GESTA0DEAGUAS/InstrumentosdeGestodeRecHid/PlanodeRecursosHi dricos/MadioParaibadoSulAgendaAzul/>. Acesso em: Abril de 2018.

LIMA, E. P. DA C., 2018 - Water and Industry: Experiences and Challenges. 1ª Edição. Infinita Imagem. Brasília. 119 pg.

MINISTÉRIO DAS CIDADES, 2013. Plano Nacional de Saneamento Básico (PLANSAB) - (Versão para apreciação do CNS, CONAMA, CNRH e CONCIDADES). Secretaria Nacional de Saneamento Ambiental. Brasília, Maio, 2013.

2015. Sistema Nacional de Informações Sobre Saneamento (SNIS) - Diagnóstico dos Serviços de Água e Esgotos - 2015. Disponível em: 〈http://www.snis.gov.br/diagnostico-agua-e-esgotos/diagnostico-ae-2015〉. Acesso em: Abril de 2018.

, 2015. Sistema Nacional de Informações Sobre Saneamento (SNIS) - Diagnóstico do manejo de Resíduos Sólidos Urbanos - 2015. Disponível em: <http://www.snis.gov.br/diagnostico-residuos-solidos/diagnostico-rs2015>. Acesso em: Abril de 2018.

MINISTÉRIO DA SAÚDE, 2006. Vigilância e controle da qualidade da água para o consumo humano. Disponível em: 〈http://bvsms.saude.gov.br/bvs/publicacoes/vigilancia_controle_qualidade_agua.pdf $>$. Acesso em: Agosto, 2018. 

Sul

OBRACZA, M e LEAL, I.F. Análise do emprego de Indicadores para aferição da eficiência na gestão de um sistema de esgotamento sanitário: 0 estudo de caso da Área de Planejamento 5 (AP. 5), RJ. In CONGRESSO SILUBESA, Florianópolis, 2015.

OBRACZKA, M, CAMPOS a M S, SILVA, D. DO R., FERREIRA G S, MURICY B e ALVES S. R., Estado da Arte e Perspectivas de Reuso de Efluentes de Sistemas de Tratamento Secundário de Esgotos Sanitários na Região Metropolitana do Rio de Janeiro, RJ. In CONGRESSO ABES FENASAN, São Paulo, 2017.

PLANO NACIONAL DE RECURSOS HÍDRICOS. Síntese Executiva - português / Ministério do Meio Ambiente, Secretaria de Recursos Hídricos - Brasília: MMA, 2006.

RANGEL, L. M. D., 2016. Avaliação dos Investimentos necessários para Universalização dos Serviços de Abastecimento de Água e Esgotamento Sanitário no RJ. Monografia final (Curso de Especialização em Eng. Sanitária e Ambiental - DESMA/FEN/UERJ).

SEBRAE. Painel Regional Médio Paraiba, 2015. Disponível em: 〈http://www.sebrae.com.br/Sebrae/Portal\%20Sebrae/UFs/RJ/Anexos/Sebrae_INFREG_2014_MedioParaiba.pdf . Acesso em: Março de 2018.

SEGURANÇA HÍDRICA. Monitoramento Qualitativo. Disponível em: 〈https://www.segurancahidricarj.com.br/qualitativo〉. Acesso em: Abril de 2018.

VON SPERLiNG T. L. e VON SPERLING M., 2013. Proposição de um sistema de indicadores de desempenho para avaliação da qualidade dos serviços de esgotamento sanitário. Revista Enga. Sanitária e Ambiental | v.l8 n.4 | out/dez 2013 | 313-322. 